\title{
CYTOKINES: THEIR ROLE IN UVEAL DISEASE
}

\author{
AIZE KIJLSTRA \\ Amsterdam, The Netherlands
}

Cytokines are small proteins (10-45 kilodaltons), that play a major role in the communication between cells throughout the body. ${ }^{1}$ Their concentration in body fluids is mainly in the picogram range, although their concentration at the site of action may be much higher since most cytokines display their activity in the direct vicinity of their cellular source. Cytokines are generally secreted immediately after their production and exert their action after binding to specific membrane-bound receptors on the same cell (autocrine), a neighbouring cell (paracrine) or after transport via the lymphatic system or blood to a distant site (hormonal).

The cytokine network is characterised by the fact that it is pleiotropic as well as redundant. The pleiotropic aspect of the network is exemplified by the observation that one cytokine may have many different functions and the redundancy is due to the fact that many cytokines have overlapping activities.

Cytokines have been grouped into different families and include the interleukins, the interferons, the colony stimulating factors, the chemokines and the growth factors. Cytokines have also been subdivided into those involved in immunoregulation, inflammation, haematopoiesis, anti-viral activity, wound healing and angiogenesis. Many cytokines are not constitutively produced by a cell and need a stimulus to induce their synthesis. Stimuli include bacterial endotoxin (monocytes, antigen (lymphocytes), Fc and complement receptors and various cytokines within the network, whereby some stimuli act synergistically on cytokine production.

\section{THE ROLE OF CYTOKINES IN THE} REGULATION OF THE IMMUNE RESPONSE

A large number of cytokines play an essential role in dictating which types of lymphocytes or antibody

From: Department Ophthalmo-Immunology of the Netherlands Ophthalmic Research Institute and the Department of Ophthalmology of the Academic Medical Centre of the University of Amsterdam, The Netherlands.

Correspondence to: Professor Dr A. Kijlstra, The Netherlands Ophthalmic Research Institute, PO Box 12141, 1100 AC Amsterdam, The Netherlands. Fax: +31-206913401; e-mail: a.kijlstra@amc.uva.nl. classes will be involved in the immune defence. ${ }^{2}$ The cytokines interferon gamma (IFN- $\gamma$ ) and interleukin (IL)-12 are involved in the generation of a delayedtype hypersensitivity response (type 1 response), whereas IL-4 and IL-13 are involved in the immediate-type hypersensitivity responses by stimulating lymphocytes that regulate $\mathrm{IgE}$ production by $\mathrm{B}$ cells (type 2 response). The balance between these two types of response is critical in determining the outcome of the immune defence mechanisms employed to combat infectious disease and is also considered to be involved in the pathogenesis of autoimmune and allergic disease.

A classical example showing the balance between the type 1 and type 2 response comes from a mouse model of leishmaniasis. Mouse strains that respond to this parasitic infection with a Th2 type response die, whereas animals showing a Th1 immune response survive. Modulation of the Th2 response in these strains to a Th1 response results in protection and survival of the mice.

Th1 responses are thought to be primarily responsible for the delayed-type hypersensitivity response and are characterised by high interferon gamma and IL-2 production and a low or absent release of IL-4. The Th1 response is considered to be beneficial in the immune response against intracellular micro-organisms whereas a Th2 response is implicated in the defence against extracellular parasites. Th2 cells produce large amounts of IL- 4 and IL-5 and play a key role in the $\operatorname{IgE}$ response. The cytokines derived from the Th2 cells deactivate macrophages and thus prevent the tissue destruction so characteristic of the Th1 response. An exaggerated Th2 response may be responsible for allergic disease and immunoglobulin-mediated autoimmunity, whereas a Th1 response causes contact hypersensitivity and autoimmune diseases such as rheumatoid arthritis and autoimmune uveitis. Several organ-specific autoimmune diseases are caused by interferon gamma producing Th1 cell and this has led to new approaches for the immunotherapy of inflammatory autoimmune diseases that are based on 
a deviation of the harmful Th1 response towards an immunosuppressive, more benign Th2 response. ${ }^{3}$

Although experimental evidence points to an important role of a Th1 type response in the pathogenesis of autoimmune uveitis, ${ }^{4}$ the evidence for such a mechanism in the pathogenesis of clinical uveitis is not very strong at present due to the lack of available ocular material from these patients. Evidence for a $\mathrm{Th} 2$ response in conjunctival allergic disorders is supported by the observation of a Th2 type of infiltrate in biopsy samples. ${ }^{5}$

Cytokines play an important role in maintaining the immunosuppressive environment of the anterior chamber. Streilein and coworkers ${ }^{6}$ have shown that aqueous-humour-derived factors modify professional antigen presenting cells in such a way that they are unable to generate a delayed-type hypersensitivity response against certain antigens, and have evidence that the responsible factors in aqueous include transforming growth factor beta (TGF- $\beta$ ). Extracts from the cornea, iris and ciliary body also exhibit as yet poorly characterised immunosuppressive activity. ${ }^{7}$

\section{ROLE OF CYTOKINES DURING INTRACULAR INFLAMMATION: EXPERIMENTAL MODELS}

Research concerning the role of cytokines in eye disease $^{8}$ can be divided into five major areas. Early work concerned the injection of purified or recombinant cytokines into the eyes of experimental animals followed by an examination of the inflammatory response. ${ }^{9.10}$ A second area deals with the detection of cytokines in ocular fluids and tissues during various experimental and clinical ocular disorders. A further area of research for investigating the role of cytokines in ocular inflammation is to alter the course of the disease by interfering in the cytokine network. A novel approach concerns the investigation of transgenic animals which express cytokine genes under the control of eye-specific proteins or the use of knockout mice that are deficient in certain cytokines. A large area of research deals with the analysis of the in vitro production of various cytokines and their antagonists by isolated ocular cells. At present the retinal pigment epithelium (RPE) cell is considered to play a key role in the regulation of the ocular inflammatory response in the posterior segment of the eye. In vitro studies have shown that this cell is capable of producing a number of inflammatory cytokines as well as the natural antagonist IL-1-RA. ${ }^{11-16}$

Numerous cytokines, including tumour necrosis factor (TNF), IL-1, IL-6, IL-8, IFN- $\gamma$ and granulocyte macrophage colony stimulating factor (GMCSF), have been shown to induce ocular inflammation after intraocular administration; IL-1 appears to cause the most serious disease. ${ }^{17-21}$ In most cases, the inflammation resembles that induced by endotoxin injection and is characterised by heavy infiltration with leucocytes and a breakdown of the bloodaqueous barrier. Cytokines appear to induce ocular inflammation only when injected directly into the eye; their systemic administration has not been described to be associated with ocular inflammation and nor have patients with high circulating cytokine levels been reported to develop ocular complications.

A classical model to study the role of cytokines in ocular disease is the so-called endotoxin-induced uveitis model. In this model a systemic (footpad, intravenous or intraperitoneal) injection of bacterial lipopolysaccharide leads to an acute ocular inflammation. The disease is characterised by a marked upregulation of various inflammatory cytokines within the uveal tissue and release of cytokines into the aqueous humour. ${ }^{8.22 .23}$

A novel approach to understanding the role of cytokines in uveal disease involves examination of eyes from transgenic animals excessively expressing a cytokine gene, or studying models of ocular inflammation in cytokine-deficient animals. An unusual syndrome of blindness has been described in transgenic mice aberrantly expressing GM-CSF. ${ }^{24}$ The increased expression of GM-CSF is associated with high expression of TNF and IL-1 by macrophages which may be held responsible for the ocular syndrome seen in these animals. Transgenic mice aberrantly expressing IL- 4 have been observed to have ocular inflammation characterised by a conjunctivitis associated with heavy infiltration with eosinophils, mast cells and macrophages. ${ }^{25}$

Aberrant expression of IFN- $\gamma$ using the rhodopsin promoter to direct expression of IFN- $\gamma$ in the retina ${ }^{26}$ results in a mouse strain that develops intraocular inflammation characterised by cell infiltration, cell proliferation, loss of photoreceptors, cataract, corneal clouding and an increased expression of MHC antigens in the retina. Intraocular injection of herpes simplex virus into the eyes of these transgenic animals showed that an increased presence of IFN- $\gamma$ induced a more vigorous immune response against the virus and protected the untreated eye from disease, whereas control animals developed bilateral retinitis. ${ }^{27}$ Targeting an increased expression of IFN- $\gamma$ in the lens also induces severe ocular abnormalities, including effects on the growth of the eye as well as an increased expression of MHC antigens in various tissues of the eye. ${ }^{28}$

Targeted mutagenesis of cytokine genes has resulted in the generation of a number of mouse strains deficient in the following cytokines: IL-1, IL2 , IL-4, IL-6, IFN- $\gamma$, TNF receptor and IFN- $\gamma$ receptor. These mice are particularly valuable in the unravelling of the role of various cytokines in 
immunoregulation and inflammation. To date, cytokine knockout animals have scarcely been employed as tools to investigate the role of cytokines in ocular inflammation. Experiments in IFN- $\gamma$ deficient mice showed that interphotoreceptor retinoid binding protein (IRBP)-induced autoimmune uveitis was not dependent on the presence of IFN- $\gamma .{ }^{29}$ Intravitreal injection of endotoxin into the vitreous of IFN- $\gamma$ knockout mice did result in a significantly lower influx of inflammatory cells compared with controls, implicating this cytokine as an important mediator in this experimental uveitis model. Future studies using the various knockout and transgenic mice in experimental models of eye disease will provide valuable information concerning the role of the cytokine network in ocular inflammation.

\section{ROLE OF CYTOKINES IN INTRAOCULAR INFLAMMATION: CLINICAL DISEASE}

The role of cytokines in the pathogenesis of clinical uveitis has been investigated by analysing aqueous or vitreous samples taken from uveitis patients for diagnostic or therapeutic purposes. Initially the studies concentrated on the detection of the inflammatory cytokines and to date an increased level of the cytokines belonging to this group such as IL-1, TNF, IL- 6 and IL- 8 have been detected in ocular fluids of uveitis patients and not in cataract or eye bank controls. ${ }^{30-35}$

IL-1 is one of the key mediators in the cytokine network and is involved in the early steps of the inflammation pathway. IL-1 is not readily detected by enzyme immunoassays and early work showing IL-1 in ocular fluids obtained from inflamed eyes were performed using bioassays. ${ }^{30}$ Recent findings indicate that IL-1 may be involved in the inflammatory response seen after cataract extraction. Evidence has been obtained that residual lens epithelial cells might play an important role in pseudophakic inflammation due to the fact that they can produce IL-1 in vitro. ${ }^{36}$ The interaction of lens epithelial cells with the plastic intraocular lens is thought to stimulate these cells to produce IL-1, which in turn activates the production of prostaglandins, ultimately causing breakdown of the blood-ocular barrier.

IL-6 has been detected in both aqueous humour and vitreous during clinical uveitis. ${ }^{8,32.33 .37}$ Raised IL-6 levels have also been found in aqueous humour following cataract removal, which indicates that IL-6 is also involved in post-cataract inflammation. ${ }^{38}$ The appearance of IL-6 in the eye is not specific for uveitis and has also been observed in vitreous samples taken from patients with proliferative vitreoretinopathy or retinal detachment. ${ }^{33,39}$ As mentioned above, in vitro experiments indicate that the RPE cells are probably the major source of IL$6 .^{11,12}$
The cytokine IL- 8 is an important chemoattractant and activator of neutrophils. ${ }^{40}$ IL-8 levels are increased in approximately $50 \%$ of patients with uveitis, ${ }^{34}$ and confirmation that the immunochemically detected IL-8 in the vitreous was biologically active was obtained by chemotactic assays and blocking experiments with monoclonal anti-human IL-8 antibodies. Further evidence that intraocular IL-8 was responsible for a granulocyte influx was obtained by showing a correlation between intraocular IL-8 levels and the levels of a specific granulocyte enzyme such as elastase. IL-8 is not present in normal vitreous but has also been found in proliferative vitreoretinal disorders. ${ }^{34,39,41}$

Not many studies have been reported on the analysis of the cytokines belonging to the immunoregulatory group. Early work identified the presence of IL-2 and IFN- $\gamma$ in uveitic eyes ${ }^{31,42}$ and recently IL-10 has been detected in aqueous or vitreous obtained from uveitis patients (Ongkosuwito et al., in preparation; see also ${ }^{43}$ ). The determination of IL-10 has been proposed by Chan et al. ${ }^{43}$ as a tool to diagnose primary intraocular lymphoma.

Whether the inflammatory response in the eye of a uveitis patient is due to a type 1 or a type 2 response has not been reported, and would necessitate the analysis of the characteristic cytokines differentiating these responses, such as IL-4 and IFN- $\gamma$. This question is currently being addressed via two different approaches. One approach involves the detection of the soluble cytokines in the intraocular fluid whereas the other involves the investigation of intracellular cytokine profiles of $\mathrm{T}$ cells derived from inflamed eyes. Preliminary results from our group revealed a lack of IL-4 activity whereas IFN- $\gamma$ was readily detected, which is suggestive of a type 1 inflammatory response (Ongkosuwito et al., in preparation).

An intraocular cytokine that has been implicated in the control of unwanted delayed-type hypersensitivity responses in the eye has been identified as TGF- $\beta-2$. TGF- $\beta$ is a multifunctional peptide that is excreted from cells in a latent inactive form. The natural activation involves cleavage of the TGF by proteolytic enzymes, which renders a TGF that can undergo interaction with its receptors. Investigation of ocular fluids from uveitis patients revealed that the total levels of TGF were not altered but that a marked decrease had occurred in the presence of free active TGF. ${ }^{44}$ Whether this was due to a block of proteolytic cleavage or to the binding of $\alpha_{2}$-macroglobulin has not been resolved. ${ }^{45}$

Analysis of cytokine receptors has shown that circulating soluble IL-2 receptor levels are raised in uveitis. ${ }^{46.47}$ Arocker-Mettinger et al. $^{46}$ reported increased levels of this receptor in patients with Fuchs' cyclitis and in children with juvenile rheuma- 
toid arthritis and uveitis, but not in other uveitis entities such as acute anterior uveitis and intermediate uveitis. A twofold increase in IL-2 receptor levels was reported by BenEzra et $a l .^{47}$ in patients with ocular Behçet's disease.

The measurement of various cytokines has not been proven to be of diagnostic value in uveitis. Further studies need to be carried out to confirm that the detection of IL-10 is valuable in the differential diagnosis of primary intraocular lymphomas.

Epiretinal membranes removed from patients during vitreoretinal surgery showed staining for TNF- $\alpha$ in $80 \%$ of samples investigated. ${ }^{48}$ Analysis of vitreous specimens taken during vitreoretinal surgery for proliferative vitreoretinopathy or diabetic retinopathy have shown that inflammatory cytokines such as IL-6, IL-8 and MCP-1 may be involved in the pathogenesis of these diseases and are instrumental in the infiltration of leucocytes. ${ }^{34,39,41}$

\section{CYTOKINES AND INTRAOCULAR INFLAMMATION: THERAPEUTIC INTERVENTION}

Since cytokines play an essential role in the pathogenesis of intraocular inflammation, new exciting approaches are being developed to control this network. Corticosteroids are the most potent inhibitors of the production of inflammatory cytokines but are frequently associated with serious side-effects such as glaucoma and cataract, which limit their prolonged use. ${ }^{49}$ Strategies are now being developed allowing a more specific action on certain individual members of the cytokine network. The possibility of making peptides or recombinant proteins in large quantities now allows the use of naturally occurring regulatory proteins such as IL-1 receptor antagonist, anti-inflammatory cytokines (IL-4, IL-10, IL-13), anti-viral interferons, soluble cytokine receptors and haematopoietic growth factors to treat various inflammatory eye diseases such as keratitis, scleritis, dry eye disease, corneal allograft rejection, Graves' ophthalmopathy, proliferative vitreoretinal disease, post-surgical inflammation and uveitis.

The paradoxical effects that have been observed in the treatment of various clinical and experimental models of eye disease have been explained by the redundant and pleiotropic nature of the network. IL-1-RA has been used to block IL-1 induced intraocular inflammation in experimental models, but could not influence the uveitis following endotoxin injection. This has been explained by the redundancy of the inflammatory response, involving more than one cytokine initiating the inflammatory response. Of interest is that IL-RA was able to inhibit the post-surgical inflammation following cataract surgery in a rabbit model. ${ }^{50}$ IL-10 has been shown to block endotoxin-induced uveitis. ${ }^{51}$ Other anti-inflammatory cytokines such as IL-4 are being used in numerous autoimmune disease models including experimental autoimmune uveitis. ${ }^{52}$

The background for using IL-4 as immunotherapy for autoimmune diseases stems from the dogma that most autoimmune diseases are considered to be Th1mediated and are characterised by a delayed-type hypersensitivity response. ${ }^{53} \mathrm{~A}$ Th2 response against the same autoantigens responsible for the disease would theoretically result in a production of the antiinflammatory cytokines IL-4, IL-10 and IL-13 and dampen down the harmful delayed-type hypersensitivity response. Since IL-4 can direct T cell differentiation towards the Th2 arm of the response, experimental immunotherapeutic strategies have been devised using exogenous IL-4 administration. Although encouraging results have been obtained in experimental allergic encephalomyelitis, treatment of Lewis rats with IL-4 paradoxically exacerbated experimental autoimmune uveitis. ${ }^{52}$

IFN- $\alpha$ has been successfully applied to treat patients with ocular manifestations of Behçet's disease ${ }^{54}$ but placebo-controlled clinical trials have not yet been published. IFN- $\gamma$ has been shown to suppress experimental autoimmune uveitis in mice, whereas treatment with anti-IFN- $\gamma$ antibodies worsens the disease. ${ }^{55}$

Other strategies which are still being studied include the use of monoclonal antibodies against individual cytokines. Anti-TNF therapy has been successfully used to treat rheumatoid arthritis patients. ${ }^{56}$ Blocking of systemic TNF during experimental endotoxin-induced uveitis paradoxically appears to worsen the disease. ${ }^{8,57,58}$ Newer developments include regulation of the cytokine network at the gene level by interfering with the promotor genes, using 'antisense oligonucleotides' to block translation of RNA and inhibiting enzymes (metalloproteinases) involved in secretion of certain cytokines. Alternatively the expression of cytokine genes could transiently be increased introducing these genes into certain tissues by targeted gene therapy. A word of caution is necessary, however, since a number of cytokines may play an important role in homeostasis and disturbances of this complex network may produce paradoxical effects.

Key words: Cytokines, Uveitis.

\section{REFERENCES}

1. Thomson AW. The cytokine handbook, 2nd ed. San Diego: Academic Press, 1994.

2. Paul WE, Seder RA. Lymphocyte response and cytokines. Cell 1994;76:241.

3. Weiner HL, Freidman A, Miller A, Khoury SJ, alSabbagh A, Santos L, et al. Oral tolerance: immunologic mechanisms and treatment of animal and human organ-specific autoimmune diseases by oral administration of autoantigens. Annu Rev Immunol 1994; 12:809-37. 
4. Saoudi A, Kuhn J, Huygen K, de Kozak Y, Velu T, Goldman M, et al. TH2 activated cells prevent experimental autoimmune uveoretinitis, a TH1-dependent autoimmune disease. Eur J Immunol 1993;23: 3096-103.

5. Calder VL, Hingorani M, Metz D, Buckley RJ, Lightman S. Differential expression of T cell cytokines in chronic allergic eye disease. Abstract book, Fourth International Symposium on Ocular. Inflammation, London, UK 1996:34.

6. Cousins SW, McCabe MM, Danielpour D, Streilein W. Identification of transforming growth factor-beta as an immunosuppressive factor in aqueous humor. Invest Ophthalmol Vis Sci 1990;32:2201-11.

7. Streilen J, Bradley D, Sano Y. Immunosuppressive properties of tissues of the ocular anterior segment. Ocul Immunol Inflamm 1996;4:57-68.

8. de Vos AF, Hoekzema R, Kijlstra A. Cytokines and uveitis: a review. Curr Eye Res 1992;11:581-97.

9. Chandler JW, Heise ER, Weiser RS. Induction of delayed-type sensitivity-like reactions in the eye by the injection of lymphokines. Invest Ophthalmol Vis Sci 1973;12:400-9.

10. Liu SH, Prendergast RA, Silverstein AM. The role of lymphokines in immunogenic uveitis. Invest Ophthalmol Vis Sci 1983;24:361-7.

11. Benson MT, Shepherd L, Rees RC, Rennie IG. Production of interleukin- 6 by human retinal pigment epithelium in vitro and its regulation by other cytokines. Curr Eye Res 1992;11:173-9.

12. Kuppner MC, McKillop-Smith S, Forrester JV. TGF- $\beta$ and IL-1 $\beta$ act in synergy to enhance IL-6 and IL-8 mRNA levels and IL- 6 production by human retinal pigment epithelial cells. Immunology 1995;84:265-71.

13. Planck SR, Huang X-N, Robertson JE, Rosenbaum T. Retinal pigment epithelial cells produce interleukin-1 and granulocyte-macrophage colony-stimulating factor in response to interleukin-1. Curr Eye Res 1993; 3:205-12.

14. Elner VM, Strieter RM, Elner SG, Baggiolini M, Lindley I, Kunkel S. Neutrophil chemotactic factor (IL-8) gene expression by cytokine-treated retinal pigment epithelial cells. Am J Pathol 1990;136:745-50.

15. Elner SG, Strieter RM, Elner VM, Rollins BJ, Del Monte MA, Kunkel SL. Monocyte chemotactic protein gene expression by cytokine-treated human retinal pigment epithelial cells. Lab Invest 1991;64:819-25.

16. Jaffe GJ, Van Le L, Valea F, Haskill S, Roberts W, Arend WP, Stuart A, Peters WP. Expression of interleukin-1, interleukin-1 and an interleukin-1 receptor antagonist in human retinal pigment epithelial cells. Exp Eye Res 1992;55:325-35.

17. Rosenbaum JT, Samples JR, Hefeneider SH, Howes EL. Ocular inflammatory effects of intravitreal interleukin 1. Arch Ophthalmol 1987;105:1117-20.

18. Hoekzema R, Murray PI, Kijlstra A. Cytokines and intraocular inflammation. Curr Eye Res 1990;9:207-11.

19. Kulkarni PS, Srinivasan BD. Cachectin: a novel polypeptide induces uveitis in the rabbit eye. Exp Eye Res 1988;46:631-3.

20. Ferrick MR, Thurau SR, Oppenheim MH, Herbort $\mathrm{CR}$, Ni M, Zachariae COC, et al. Ocular inflammation stimulated by intravitreal interleukin-8 and interleukin-1. Invest Ophthalmol Vis Sci 1991;32:1534-9.

21. Bhattacherjee P, Henderson B. Inflammatory responses to intraocularly injected interleukin 1. Curr Eye Res 1987;6:929-34.

22. de Vos AF, Klaren VNA, Kijlstra A. Expression of multiple cytokines and interleukin-1 receptor antago- nist in the uvea and retina during endotoxin-induced uveitis in the rat. Invest Ophthalmol Vis Sci 1994; 35:3873-83.

23. de Vos AF, van Haren MAC, Verhagen C, Hoekzema R, Kijlstra A. Kinetics of intraocular tumour necrosis factor and interleukin-6 in endotoxin-induced uveitis in the rat. Invest Ophthalmol Vis Sci 1994;35:1100-6.

24. Lang RA, Cuthbertson RA, Dunn AR. TNF alpha, IL-1 alpha and bFGF are implicated in the complex disease of GM-CSF transgenic mice. Growth Factors 1992;6:131-8.

25. Dvorak AM, Tepper RI, Weller PF, Morgan ES, Estrella P, Monahan-Earley RA, Galli SJ. Piecemeal degranulation of mast cells in the inflammatory eyelid lesions of interleukin-4 transgenic mice: evidence of mast cell histamine release in vivo by diamine oxidasegold enzyme-affinity ultrastructural cytochemistry. Blood 1994;83:3600-12.

26. Geiger K, Howes E, Gallina M, Huang XJ, Travis GH, Sarvetnick N. Transgenic mice expressing IFN-gamma in the retina develop inflammation of the eye and photoreceptor loss. Invest Ophthalmol Vis Sci 1994;35:2667-81.

27. Geiger K, Howes EL, Sarvetnick N. Ectopic expression of gamma interferon in the eye protects transgenic mice from intraocular herpes simplex virus type 1 infections. J Virol 1994;68:5556-67.

28. Egwuagu CE, Sztein J, Chan CC, Reid W, Mahdi R, Nussenblatt RB, Chepelinsky AB. Ectopic expression of gamma interferon in the eyes of transgenic mice induces ocular pathology and MHC class II gene expression. Invest Ophthalmol Vis Sci 1994;35:332-41.

29. Jones LS, Rizzo LV, Agarwal R, Silver PB, Caspi RR. Interferon gamma (IFN- $\gamma$ ) deficient mice are susceptible to induction of experimental autoimmune uveitis (EAU) [abstract]. Invest Ophthalmol Vis Sci 1996;37:S896.

30. Franks WA, Limb GA, Stanford MR, Ogilvie J, Wolstencroft RA, Chignell AH, Dumonde DC. Cytokines in human intraocular inflammation. Curr Eye Res 1992;11:187-91.

31. Wakefield D, Lloyd A. The role of cytokines in the pathogenesis of inflammatory eye disease. Cytokine 1992;4:1-5.

32. Murray PI, Hoekzema R, van Haren MAC, de Hon FD, Kijlstra A. Aqueous humor interleukin-6 levels in uveitis. Invest Ophthalmol Vis Sci 1990;31:917-20.

33. de Boer JH, van Haren MAC, de Vries-Knoppert WAEJ, Baarsma GS, de Jong PVTM, Postema FJ, et al. Analysis of IL-6 levels in human vitreous fluid obtained from uveitis patients, patients with proliferative intraocular disorders and eye bank eyes. Curr Eye Res 1992;11:181-6.

34. de Boer JH, Hack CE, Verhoeven AJ, Baarsma GS, de Jong PTVM, Rademakers AJ, et al. Chemoattractant and neutrophil degranulation activities related to interleukin-8 in vitreous fluid in uveitis and vitreoretinal disorders. Invest Ophthalmol Vis Sci 1993; 34:3376-85.

35. Mondino BJ, Sidikaro Y, Mayer FJ, Sumner HL. Inflammatory mediators in the vitreous humor of AIDS patients with retinitis. Invest Ophthalmol Vis Sci 1990;30:798-804.

36. Nishi O, Nishi K, Imanishi M. Synthesis of interleukin-1 and prostaglandin $\mathrm{E}_{2}$ by lens epithelial cells of human cataracts. Br J Ophthalmol 1992;76:338-41.

37. van der Lelij A, Rothova A, de Vries JP, Vetter JCM, van Haren MAC, Stilma JS, Kijlstra A. Analysis. of 
aqueous humour in ocular onchocerciasis. Curr Eye Res 1991;10:169-76.

38. Malecaze F, Chollet P, Cavrois E, Vita N, Arne JL, Ferrara P. Role of interleukin 6 in the inflammatory response after cataract surgery: an experimental and clinical study. Arch Ophthalmol 1991;109:1681-3.

39. Kauffmann DJ, van Meurs JC, Mertens DA, Peperkamp E, Master C, Gerritsen ME. Cytokines in vitreous humor: interleukin-6 is elevated in proliferative vitreoretinopathy. Invest Ophthalmol Vis Sci 1994; 35:900-6.

40. Baggiolini M, Dahinden CA. CC chemokines in allergic inflammation. Immunol Today 1994;15:127-33.

41. Elner SG, Elner VM, Jaffe GJ, Stuart A, Kunkel SL, Streiter RM. Cytokines in proliferative diabetic retinopathy and proliferative vitreoretinopathy. Curr Eye Res 1995;14:1045-53.

42. Hooks JJ, Chan CC, Detrick B. Identification of the lymphokines, interferon-gamma and interleukin-2, in inflammatory eye diseases. Invest Ophthalmol Vis Sci 1988;29:1444-51.

43. Chan CC, Scott M, Whitcup MD, Solomon D, Nussenblatt RB. Interleukin-10 in the vitreous of patients with primary intraocular lymphoma. Am J Ophthalmol 1995;120:671-3.

44. de Boer JH, Limpens J, Orengo-Nania S, de Jong PTVM, La Heij E, Kijlstra A. Low mature TGF- $\beta 2$ levels in aqueous humor. Invest Ophthalmol Vis Sci 1994;35:3702-10.

45. Schultz MW, Chamberlain CG, McAvoy JW. Inhibition transforming growth factor- $\beta$-induced cataractous changes in lens explants by ocular media and $\alpha 2$ macroglobulin. Invest Ophthalmol Vis Sci 1996;37: 1509-19.

46. Arocker-Mettinger E, Asenbauer T, Ulbrich S, Grabner G. Serum interleukin 2-receptor levels in uveitis. Curr Eye Res 1990;9:25-9.

47. Ben Ezra D, Maftzir G, Kalichman I, Barak V. Serum levels of interleukin-2 receptor in ocular Behçet's disease. Am J Ophthalmol 1993;115:26-30.

48. Limb GA, Chignell AH, Green W, Leroy F, Dumonde DC. Distribution of TNF-alpha and its reactive vascular adhesion molecules in fibrovascular membranes of proliferative diabetic retinopathy. $\mathrm{Br} \mathbf{J}$ Ophthalmol 1996;80:168-73.

49. Suttorp-Schulten MSA, Jager MJ, Kijlstra A. Recent developments in the treatment of posterior uveitis. Ocul Immunol Inflamm 1996;4:207-17.

50. Nishi O, Nishi K, Ohmoto Y. Effect of interleukin 1 receptor antagonist on the blood-aqueous barrier after intraocular lens implantation. $\mathrm{Br} \mathrm{J}$ Ophthalmol 1994;78:917-20.

51. Rosenbaum JT, Angell E. Paradoxical effects of IL-10 in endotoxin-induced uveitis. J Immunol 1995;155: 4090-4.

52. Ramanathan S, de Kozak Y, Saoudi A, Goureau O, van der Meide PH, Druet P, Bellon B. Recombinant IL-4 aggravates experimental autoimmune uveoretinitis in rats. J Immunol 1996;157:2209-15.

53. Röcken M, Racke M, Shevach EM. IL-4-induced immune deviation as antigen-specific therapy for inflammatory autoimmune disease. Immunol Today 1996;17:225-31.

54. Feron EJ, Rothova A, van Hagen PM, Baarsma GS, Suttorp-Schulten MSA. Interferon- $\alpha_{2 b}$ for refractory ocular Behçet's disease. Lancet 1994;343:1428.

55. Caspi RR, Chan CC, Grubbs BG, Silver PB, Wiggert $\mathrm{B}$, Parsa CF, Bahmanyar S, et al. Endogenous systemic IFN-gamma has a protective role against ocular autoimmunity in mice. J Immunol 1994;152:890-9.

56. Elliot MJ, Maini RN, Feldmann M, Long-Fox A, Charles $\mathrm{P}$, Katsikis $\mathrm{F}$, et al. Treatment of rheumatoid arthritis with chimeric monoclonal antibodies to tumor necrosis factor alpha. Arthritis Rheum 1993; 36:1681-90.

57. Kasner L, Chan CC, Whitcup SM, Gery I. The paradoxical effect of tumor necrosis factor alpha $(\mathrm{TNF}-\alpha)$ in endotoxin-induced uveitis. Invest Ophthalmol Vis Sci 1993;34:2911-7.

58. de Vos AF, van Haren MAC, Verhagen C, Hoekzema R, Kijlstra A. Systemic anti-tumor necrosis factor antibody treatment exacerbates endotoxin-induced uveitis in the rat. Exp Eye Res 1995;61:667-75. 